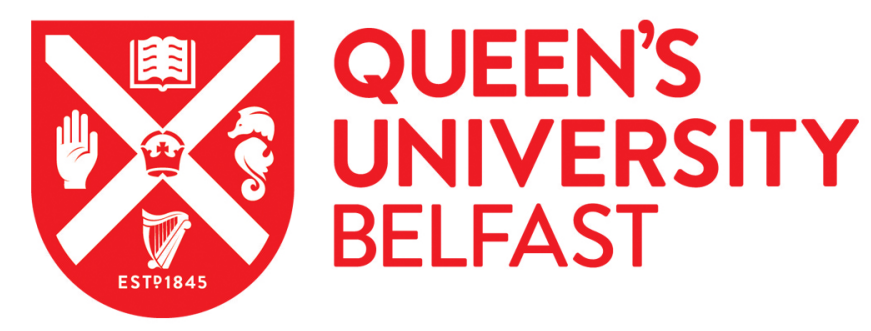

\title{
The Adaptiveness in Stock Markets: Testing the Stylized Facts in the DAX 30
}

He, X-Z., \& Li, Y. (2017). The Adaptiveness in Stock Markets: Testing the Stylized Facts in the DAX 30. Journal of evolutionary economics, 27(5), 1071-1094. https://doi.org/10.1007/s00191-017-0505-9

Published in:

Journal of evolutionary economics

Document Version:

Peer reviewed version

Queen's University Belfast - Research Portal:

Link to publication record in Queen's University Belfast Research Portal

Publisher rights

(C) 2017 Springer-Verlag Berlin Heidelberg.

This work is made available online in accordance with the publisher's policies. Please refer to any applicable terms of use of the publisher.

\section{General rights}

Copyright for the publications made accessible via the Queen's University Belfast Research Portal is retained by the author(s) and / or other copyright owners and it is a condition of accessing these publications that users recognise and abide by the legal requirements associated with these rights.

Take down policy

The Research Portal is Queen's institutional repository that provides access to Queen's research output. Every effort has been made to ensure that content in the Research Portal does not infringe any person's rights, or applicable UK laws. If you discover content in the Research Portal that you believe breaches copyright or violates any law, please contact openaccess@qub.ac.uk. 


\title{
THE ADAPTIVENESS IN STOCK MARKETS: TESTING THE STYLIZED FACTS IN THE DAX 30
}

\author{
XUE-ZHONG HE ${ }^{\dagger}$, AND YOUWEI LI ${ }^{\ddagger}$ \\ $\dagger$ University of Technology Sydney \\ Business School, Finance Discipline Group \\ PO Box 123 Broadway, NSW 2007, Australia \\ tony.he1@uts.edu.au \\ and \\ $\ddagger$ Queen’s University of Belfast \\ School of Management
}

Riddel Hall, 185 Stranmillis Road, BT9 5EE, Belfast, UK

$$
\text { y. li@qub.ac.uk }
$$

\begin{abstract}
By testing a simple asset pricing model of heterogeneous agents to characterize the power-law behavior of the DAX 30 from 1975 to 2007, we provide supporting evidence on empirical findings that investors and fund managers use combinations of fixed and switching strategies based on fundamental and technical analysis when making investment decisions. A mechanism analysis based on the calibrated model provides an insight into the explanatory power of rational switching behavior of investors on the volatility clustering and long range dependence in return volatility.
\end{abstract}

Keywords: Adaptive switching, fundamental and technical analysis, stylized facts, power-law, tail index.

JEL Classification: C15, D84, G12

Date: Latest version: July 26, 2016.

Acknowledgements: This research was initiated and conducted during He's visit at Queen's University Belfast and Li's visit to Quantitative Finance Research Center at University of Technology Sydney, whose hospitality they gratefully acknowledge. Financial support from the Australian Research Council (ARC) under discovery grant (DP130103210) is also gratefully acknowledged. We benefited from detailed comments of two anonymous referees, Roberto Dieci (the Guest Editor), Michael Goldstein and Cars Hommes on the earlier version of this paper. The usual caveats apply.

$\S$ Corresponding author. 


\section{INTRODUCTION}

The use of fundamental and technical analysis by financial market professionals is well documented. ${ }^{1}$ Empirical evidence suggests that investors and fund managers use combinations of fixed and switching strategies based on fundamental and technical analysis when making investment decisions. Recent laboratory experiments (e.g. Hommes et al., 2005 and Anufriev and Hommes, 2012) provide further evidence on that agents use simple "rule of thumb" trading strategies and are able to coordinate on a common prediction rule, showing that heterogeneity in expectations is crucial to describe individual forecasting and aggregate price behavior. Many heterogeneous agent models based on investors' behavior of using fixed and, in particular, switching strategies can replicate volatility clustering and long range dependence in return volatility. However, an empirical test of such switching model is still a challenging task and this paper is aimed to address this challenge. In this paper we empirically test a simple asset pricing model of heterogeneous agents using both fixed and switching strategies and show that the model is able to characterize the power-law behavior of the daily DAX 30 index from 1975 to 2007. More explicitly, we show that the market is dominated by investors who constantly switch between fundamental and trend following strategies, although some investors never change their strategies over the time. The results provide a strong support to the empirical evidence and laboratory experiments. Consequently, we provide a different insight into the explanatory power of heterogeneous agent models to financial markets.

This paper is largely motivated by the recent literature on heterogeneity and bounded rationality. Due to limited information and endogenous uncertainty of the state of the world, investors are prevented from forming and solving life-time optimization problems in favor of more simple reasoning and rules of thumb (Shefrin, 2005). In general, investors are boundedly rational by making optimal decisions based on their limited information and expectations (Sargent, 1993). There is a growing evidence on investors' heterogeneity and bounded rationality, which has profound consequences for the interpretation of empirical evidence and the formulation of economic policy (Heckman, 2001). Research into asset pricing and financial market dynamics resulting from bounded rationality and interaction of adaptively heterogeneous traders has flourished over the last three decades and various heterogeneous agent models (HAMs) have

\footnotetext{
${ }^{1}$ See, for example, Allen and Taylor (1990), Taylor and Allen (1992), Menkhoff (1998) and Cheung et al., (2004) for foreign exchange rate markets and Menkhoff (2010) for fund managers.
} 
been developed. ${ }^{2}$ To explore the role of agents' heterogeneity in financial markets, the market dominance of different trading strategies represented by different types of traders plays a central role in market price behavior. It has been modelled either implicitly by examining their relative activity impacts, such as Day and Huang (1990) and Chiarella (1992) in early literature, or explicitly by examining their market fractions, such as Lux (1995), Brock and Hommes (1998), and Dieci, Foroni, Gardini and He (2006). The HAMs have successfully explained market booms, crashes, and deviations of the market price from the fundamental price. They are also able to replicate various stylized facts (including excess volatility, excess skewness, fat tails, volatility clustering and power-law behavior in return volatility) observed in financial markets. ${ }^{3}$

The promising perspectives of the HAMs have motivated further empirical studies. Focusing on the model of Dieci et al. (2006), which allows for agents either having fixed strategies or switching their strategies based on past performance over time, we extend the model to include noise traders to rationalize the market noise in the model, which plays a very important role in explaining the power-law behavior. Our main contribution is to systematically calibrate a number of structural parameters of the model and subsequently perform series of formal econometric tests, showing that the calibrated model with both fixed and switching strategies is well able to replicate a large number of stylized facts. We therefore provide a different insight into the explanatory power of rational switching behavior of investors on the volatility clustering and long range dependence in return volatility.

This paper is closely related to a growing literature on the calibration and estimation of the HAMs in which the heterogeneity has been modeled through the well-known fundamentalists and chartists approach. These models have been successfully used to empirically explain speculation and bubble-like behavior in financial markets. ${ }^{4}$ Recently, $\mathrm{He}$ and Li (2015) estimate a simple market fraction asset pricing model with heterogenous agents in which agents use fixed

\footnotetext{
${ }^{2}$ See, for example, Frankel and Froot (1990), Day and Huang (1990), Chiarella (1992), Lux (1995, 1998), Brock and Hommes (1998), Lux and Marchesi (1999), Hommes (2001), Chen and Yeh (2002), Farmer and Joshi (2002), Chiarella et al. (2002), Chiarella and He (2002, 2003), and De Grauwe and Grimaldi (2006).

${ }^{3}$ We refer the reader to Hommes (2006), LeBaron (2006), Chiarella et al. (2009), Lux (2009b), and Chen et al. (2012) for surveys of recent developments in this literature.

${ }^{4}$ See, for instance, earlier works by Vigfusson (1997), Baak (1999), Chavas (2000), and for stock markets (Boswijk et al., 2007; Franke, 2009; Franke and Westerhoff, 2011, 2012; Chiarella et al., 2012, 2014; He and Li, 2015), foreign exchange markets (Westerhoff and Reitz, 2003; De Jong et al., 2010; ter Ellen et al., 2013), mutual funds (Goldbaum and Mizrach, 2008), option markets (Frijns et al., 2010), oil markets (ter Ellen and Zwinkels, 2010), and sovereign European CDS markets (Chiarella et al., 2015). Also, HAMs have been estimated with contagious interpersonal communication by Gilli and Winker (2003), Alfarano et al. (2005), Lux (2009a, 2012), and other works reviewed in Li et al. (2010) and Chen et al. (2012).
} 
strategies (without switching). For the estimated model, we show that the autocorrelations (of returns, absolute returns and squared returns) of the market fraction model share the same pattern and the power-law behaviors as those of the DAX 30. The results strongly support the explanatory power of the heterogeneous agents models. However, whether switching models can be tested empirically to explain volatility clustering and power-law behavior is less clear. For example, Amilon (2008) estimates two specifications of the extended Brock and Hommes switching models described in De Grauwe and Grimaldi (2006). He concludes that the simple prototype models he estimated seems to have potential to explain empirical facts, however the fit is generally not quite satisfactory. Intuitively, with rational switching behavior of investors, we would expect switching models to work better empirically. The difficulties come from the nonlinearity and complexity of the HAMs, together with many parameters. ${ }^{5}$ In this paper, following Li et al. (2010) and $\mathrm{He}$ and $\mathrm{Li}$ (2015) we take the weak econometric interpretation of Geweke (2006) based on the power-law decay patterns of the autocorrelation of returns, the squared returns and the absolute returns for the DAX 30 stock market daily closing price index. We do this by choosing the interesting parameters in the whole model class that minimize the distance between particular actual data based autocorrelations and HAMs based autocorrelations. Different from He and Li (2015), we model the switching behavior of some investors, in addition to other investors who use fixed strategies. By conducting econometric analysis via Monte Carlo simulations of the model with estimated parameters, we show that the autocorrelation patterns, the estimates of the power-law decay indices, (FI)GARCH parameters, and tail index of the model match closely to the corresponding estimates for the DAX 30. Our results therefore provide a strong support to the empirical evidence on the popularity of fundamental and technical analysis, boundedly rational and adaptive switching behavior of investors in financial markets.

The paper is structured as follows. Section 2 reformulates the adaptive asset pricing model developed in Dieci et al. (2006) to include noise traders. Section 3 calibrates the model to characterize the power-law behavior of the DAX 30. We also conduct formal tests to see how well the calibrated model is able to describe the characteristics of the DAX 30. Section 4 presents an explanation on the generating mechanism of the power-law behavior of the model. Section 5 concludes.

\footnotetext{
${ }^{5}$ We refer to He and $\mathrm{Li}$ (2015) for a detailed discussion on these issues.
} 


\section{THE MODEL}

Empirical evidence (Allen and Taylor, 1990 and Taylor and Allen, 1992) suggests that the proportions of agents relying on particular strategies such as technical and fundamental analysis may vary over time, although there are certain confident agents who do not change their strategy over time. Recently, Menkhoff (2010) analyzes survey evidence from 692 fund managers in five countries. He finds that the share of fund managers that put at least some importance on technical analysis is very large. Though technical analysis does not dominate the decisionmaking of fund managers in general, at a forecasting horizon of weeks, Menkhoff (2010) finds that technical analysis is the most important form of analysis and is thus more important than fundamental analysis, which is in line with findings from foreign exchange in Menkhoff (1998) and Cheung et al. (2004). Menkhoff (2010) strongly supports the view that heterogeneous agents have different sets of information or different beliefs about market processes. Also the use of technical analysis seems to react to this view with trend-following behavior (and also by relying more strongly on momentum and contrarian investment strategies), believing that psychological factors are important and herding is beneficial. This view has also been shared by recent laboratory experiments in Hommes et al. (2005) and Anufriev and Hommes (2012). They show that agents using simple "rule of thumb" trading strategies are able to coordinate on a common prediction rule. Therefore heterogeneity in expectations and the adaptive behavior are crucial to describe individual forecasting and aggregate price behavior.

Based on the empirical evidence, Dieci et al. (2006) extend early HAMs of Brock and Hommes (1998) by considering a more general setup that market fractions have both fixed and adaptive switching components. In each trading period agents are assumed to be distributed among two groups, relying upon different predictors (or strategies, or behavioral rules), fundamental traders (or fundamentalists) and trend followers (or chartists). The market fractions in a given period are partially determined by the past performance of the strategies over time and partially fixed. In other words, a switching component is introduced to characterize adaptively rational behavior of agents who choose different strategies over time according to their performance. A constant component of agents is used to represent agents who are confident and stay with their strategies over time. While the fixed fraction component expresses the market mood, the switching fraction component captures the effect of evolutionary adaption. The focus of 
Dieci et al. (2006) is to explore the complicated price dynamics of the corresponding nonlinear deterministic model, while the focus of this paper is on the empirical testing of the model to characterize the power-law behavior of the DAX 30 . To calibrate the model, we find that the additive market noise plays an important role. To rationalize the additive market noise, apart from the fundamentalists and trend followers in the model of Dieci et al. (2006), we also introduce noise traders who play an important role in financial market (see, for example, Delong et al. 1990). We show that the resulting model is actually the same as the model of Dieci et al. (2006) with a market noise.

Consider an asset pricing model with one risky asset and one risk free asset that is assumed to be perfectly elastically supplied at gross return $R=1+r / K$, where $r$ is the constant risk free rate per annum and $K$ is the frequency of trading period per year. Let $p_{t}$ be the (ex dividend) price per share of the risky asset and $\left\{D_{t}\right\}$ the stochastic dividend process of the risky asset at time $t$. There are three types of traders (or investors/agents), fundamental traders (or fundamentalists), trend followers (or chartists) and noise traders, denoted by type 1,2 and 3 traders respectively. Let $Q_{i, t}(i=1,2,3)$ be their market fractions at time $t$, respectively. We assume that there is a fixed fraction of noise traders, denoted by $n_{3}$. Among $1-n_{3}$, the market fractions of the fundamentalists and trend followers have fixed and time varying components. Denote by $n_{1}$ and $n_{2}$ the fixed proportions of fundamentalists and trend followers among $1-n_{3}$, respectively. Then $\left(1-n_{3}\right)\left(n_{1}+n_{2}\right)$ represents the proportion of traders who stay with their strategies over time, while $\left(1-n_{3}\right)\left[1-\left(n_{1}+n_{2}\right)\right]$ is the proportion of traders who may switch between the two types. Among the "switching" traders, we denote $n_{1, t}$ and $n_{2, t}=1-n_{1, t}$ the proportions of fundamentalists and trend followers at time $t$, respectively. It follows that the market fractions $\left(Q_{1, t}, Q_{2, t}, Q_{3, t}\right)$ at time $t$ are expressed by

$Q_{1, t}=\left(1-n_{3}\right)\left[n_{1}+\left(1-n_{1}-n_{2}\right) n_{1, t}\right], \quad Q_{2, t}=\left(1-n_{3}\right)\left[n_{2}+\left(1-n_{1}-n_{2}\right) n_{2, t}\right], \quad Q_{3, t}=n_{3}$.

Denote $n_{0}=n_{1}+n_{2}, m_{0}=\left(n_{1}-n_{2}\right) / n_{0}$ and $m_{t}=n_{1, t}-n_{2, t}$. Then the market fractions at time $t$ can be rewritten as

$$
\left\{\begin{array}{l}
Q_{1, t}=\frac{1}{2}\left(1-n_{3}\right)\left[n_{0}\left(1+m_{0}\right)+\left(1-n_{0}\right)\left(1+m_{t}\right)\right] \\
Q_{2, t}=\frac{1}{2}\left(1-n_{3}\right)\left[n_{0}\left(1-m_{0}\right)+\left(1-n_{0}\right)\left(1-m_{t}\right)\right] \\
Q_{3, t}=n_{3}
\end{array}\right.
$$


Let $R_{t+1}:=p_{t+1}+D_{t+1}-R p_{t}$ be the excess return per share in $(t, t+1)$. For $h=1,2$, let $E_{h, t}$ and $V_{h, t}$ be the conditional expectation and variance of type $h$ traders. Let $W_{h, t}$ be investor's wealth at time $t$ and $z_{h, t}$ the number of shares of the risky asset held by the investor from $t$ to $t+1$. Then the wealth of investor of type $h$ at $t+1$ is given by $W_{h, t+1}=R W_{h, t}+$ $z_{h, t}\left(p_{t+1}+D_{t+1}-R p_{t}\right)$. Assume that traders maximize the expected utility of wealth function $U_{h}(W)=-\exp \left(-a_{h} W\right)$, where $a_{h}$ is the risk aversion coefficient of type $h$ traders. Then, under the standard conditional normality assumption, the demand $z_{h, t}$ of a type $h$ trader on the risky asset is given by $z_{h, t}=E_{h, t}\left(R_{t+1}\right) /\left(a_{h} V_{h, t}\left(R_{t+1}\right)\right)$.

Assume the demand of the noise traders is given by $\xi_{t} \sim N\left(0, \sigma_{\xi}^{2}\right)$, which is an i.i.d. random variable. With zero supply of outside shares, the population weighted average excess demand $Z_{e, t}$ at time $t$ is given by

$$
Z_{e, t} \equiv Q_{1, t} z_{1, t}+Q_{2, t} z_{2, t}+n_{3} \xi_{t}
$$

Following Chiarella and He (2003), the market price in each trading period is determined by a market maker $^{6}$ who adjusts the price as a function of the excess demand. The market maker takes a long position when $Z_{e, t}<0$ and a short position when $Z_{e, t}>0$. The market price is adjusted according to

$$
p_{t+1}=p_{t}+\lambda Z_{e, t}
$$

where $\lambda$ denotes the speed of price adjustment of the market maker. Denote $\mu=\left(1-n_{3}\right) \lambda$ and $\sigma_{\delta}=\lambda n_{3} \sigma_{\xi}$. Then equation (2.2) becomes

$$
p_{t+1}=p_{t}+\mu Z_{e, t}+\delta_{t}
$$

where $Z_{e, t}=q_{1, t} z_{1, t}+q_{2, t} z_{2, t}$ and $\delta_{t} \sim N\left(0, \sigma_{\delta}^{2}\right)$ with $q_{i, t}=Q_{i, t} /\left(1-n_{3}\right)$ for $i=1,2$. The price equation (2.3) is exactly the model developed in Dieci et al. (2006).

For completeness, we now describe briefly the heterogeneous beliefs of the fundamentalists and trend followers and the adaptive switching mechanism and refer the readers to Dieci et al. (2006) and $\mathrm{He}$ and $\mathrm{Li}(2008,2015)$ for the details. Fundamental traders are assumed to have some information on the fundamental value $p_{t+1}^{*}$ of the risky asset at time $t .^{7}$ They believe

\footnotetext{
${ }^{6}$ Different from the Walrasian equilibrium price mechanism used in Boswijk et al. (2007), we use market maker partial equilibrium mechanism for the convenience of calibration. The market maker mechanism has often been used in HAMs for its simplicity and convenience.

${ }^{7}$ There is a subtle difference on the information about the fundamental values among investors. For these investors who have fixed strategies, only the fundamentalists, not the trend followers, have the information about the fundamental value. This is the assumption made in the market fraction model of He and Li (2015). However,
} 
that the stock price may be driven away from the fundamental price in the short run, but it will eventually return to the fundamental value in the long-run. Thus the conditional mean and variance of the price for the fundamental traders are assumed to follow

$$
E_{1, t}\left(p_{t+1}\right)=p_{t}+(1-\alpha)\left(p_{t+1}^{*}-p_{t}\right), \quad V_{1, t}\left(p_{t+1}\right)=\sigma_{1}^{2},
$$

where $\sigma_{1}^{2}$ is a constant variance on the price. The speed of adjustment towards the fundamental price is represented by $(1-\alpha)$, where $0<\alpha<1$. An increase in $\alpha$ may thus indicate less confidence on the convergence to the fundamental price, leading to a slower adjustment.

Unlike the fundamental traders, trend followers are assumed to extrapolate the latest observed price deviation from a long run sample mean price. More precisely, their conditional mean and variance are assumed to follow

$$
E_{2, t}\left(p_{t+1}\right)=p_{t}+\gamma\left(p_{t}-u_{t}\right), \quad V_{2, t}\left(p_{t+1}\right)=\sigma_{1}^{2}+b_{2} v_{t}
$$

where $\gamma \geq 0$ measures the extrapolation from the trend, $u_{t}$ and $v_{t}$ are sample mean and variance, respectively, which follow

$$
u_{t}=\delta u_{t-1}+(1-\delta) p_{t}, \quad v_{t}=\delta v_{t-1}+\delta(1-\delta)\left(p_{t}-u_{t-1}\right)^{2}
$$

representing limiting processes of geometric decay processes when the memory lag tends to infinity. ${ }^{8}$ Here $b_{2} \geq 0$ measures the sensitivity to the sample variance and $\delta \in(0,1)$ measures the geometric decay rate. Note that a constant variance is assumed for the fundamentalists who believe the mean reverting of the market price to the fundamental price; while a time-varying component of the variance for the trend followers reflects the extra risk they take by chasing the trend.

We now specify how traders compute the conditional variance of the dividend $D_{t+1}$ and of the excess return $R_{t+1}$ over the trading period. For simplicity we assume that traders share homogeneous belief about the dividend process and that the trading period dividend $D_{t}$ is i.i.d. and normally distributed with mean $\bar{D}$ and variance $\sigma_{D}^{2}$. The common estimate of the variance of the

for those investors who are switching between the fundamentalists and trend followers, the information about the fundamental value is know for them, which is the common assumption on the switching HAMs.

${ }^{8}$ With a geometric decaying probability distribution $(1-\delta)\left\{1, \delta, \delta^{2}, \delta^{3}, \cdots\right\}$ over the historical prices $\left\{p_{t}, p_{t-1}, p_{t-2}, p_{t-3}, \cdots,\right\}, u_{t}$ and $v_{t}$ are the corresponding sample mean and variance. See He (2003) for a detailed discussion on the process. 
dividend $\left(\sigma_{D}^{2}\right)$ is assumed to be proportional to the variance of the fundamental price, with no correlation between price and dividend. It follows that traders' conditional variances of the excess return can be estimated ${ }^{9}$ as $V_{1, t}\left(R_{t+1}\right)=\left(1+r^{2}\right) \sigma_{1}^{2}$ and $V_{2, t}\left(R_{t+1}\right)=\sigma_{1}^{2}\left(1+r^{2}+b v_{t}\right)$, where $b=b_{2} / \sigma_{1}^{2}$. Denote by $p^{*}=\bar{D} /(R-1)=(K / r) \bar{D}$ the long-run fundamental price. Using (2.4) and (2.5), it turns out that traders' optimal demands are determined by

$$
z_{1, t}=\frac{(\alpha-1)\left(p_{t}-p_{t+1}^{*}\right)-(R-1)\left(p_{t}-p^{*}\right)}{a_{1}\left(1+r^{2}\right) \sigma_{1}^{2}}, \quad z_{2, t}=\frac{\gamma\left(p_{t}-u_{t}\right)-(R-1)\left(p_{t}-p^{*}\right)}{a_{2} \sigma_{1}^{2}\left(1+r^{2}+b v_{t}\right)} .
$$

Denote by $\pi_{h, t+1}$ the realized profit, or excess return, between $t$ and $t+1$ by traders of type $h, \pi_{h, t+1}=z_{h, t}\left(p_{t+1}+D_{t+1}-R p_{t}\right)=W_{h, t+1}-R W_{h, t}$ for $h=1,2$. Following Brock and Hommes $(1997,1998)$, the proportion of "switching" traders at time $t+1$ is determined by

$$
n_{h, t+1}=\frac{\exp \left[\beta\left(\pi_{h, t+1}\right)\right]}{\sum_{i} \exp \left[\beta\left(\pi_{i, t+1}\right)\right]}, \quad h=1,2,
$$

where parameter $\beta$ is the intensity of choice measuring the switching sensitivity of the population of adaptively rational traders to the better profitable strategy. Together with (2.1) the market fractions and asset price dynamics are determined by the following random discrete-time dynamic system ${ }^{10}$

$$
\begin{aligned}
p_{t+1} & =p_{t}+\mu\left(q_{1, t} z_{1, t}+q_{2, t} z_{2, t}\right)+\delta_{t}, \quad \delta_{t} \sim \mathcal{N}\left(0, \sigma_{\delta}^{2}\right), \\
u_{t} & =\delta u_{t-1}+(1-\delta) p_{t}, \\
v_{t} & =\delta v_{t-1}+\delta(1-\delta)\left(p_{t}-u_{t-1}\right)^{2}, \\
m_{t} & =\tanh \left\{\frac{\beta}{2}\left(z_{1, t-1}-z_{2, t-1}\right)\left(p_{t}+D_{t}-R p_{t-1}\right)\right\}, \\
D_{t} & =\bar{D}+\sigma_{D} \nu_{t}, \quad \nu_{t} \sim N(0,1),
\end{aligned}
$$

\footnotetext{
${ }^{9}$ The long-run fundamental value is given by $p^{*}=(K \bar{D}) / r$, where $K \bar{D}$ is the average annual dividend. Let $\sigma \bar{p}$ be the annual volatility of the price $p$, where $\sigma$ represents the annual volatility of 1 dollar invested in the risky asset. Under independent price increments, the trading period variance of the price can be estimated as $\sigma_{1}^{2}=$ $\left(p^{*} \sigma\right)^{2} / K$. Denote by $D_{A}$ and $\sigma_{D_{A}}^{2}$ the annual dividend and its variance and assume an approximate relationship $D_{A}=r p$ between annual dividend and price. Then one gets $\sigma_{D_{A}}^{2}=r^{2}\left(\sigma p^{*}\right)^{2}$ and therefore $\sigma_{D}^{2}=\sigma_{D_{A}}^{2} / K=$ $r^{2}\left(\sigma p^{*}\right)^{2} / K=r^{2} \sigma_{1}^{2}$. Assuming zero correlation between price and dividend at trading period frequency, one then obtain $V_{1, t}\left(R_{t+1}\right)=\left(1+r^{2}\right) \sigma_{1}^{2}$ and $V_{2, t}\left(R_{t+1}\right)=\sigma_{1}^{2}\left(1+r^{2}\right)+b_{2} v_{t}$.

${ }^{10}$ Here the hyperbolic function $\tanh (x)$ is defined by $\tanh (x)=\left(e^{x}-e^{-x}\right) /\left(e^{x}+e^{-x}\right)$.
} 
where $z_{1, t}$ and $z_{2, t}$ are given by (2.6). The fundamental price is assumed to follow a random walk, such that ${ }^{11}$

$$
p_{t+1}^{*}=p_{t}^{*} \exp \left(-\frac{\sigma_{\epsilon}^{2}}{2}+\sigma_{\epsilon} \epsilon_{t+1}\right), \quad \epsilon_{t} \sim \mathcal{N}(0,1), \quad \sigma_{\epsilon} \geq 0, \quad p_{0}^{*}=p^{*}>0
$$

where $\epsilon_{t}$ is independent of the noisy demand process $\delta_{t}$. The corresponding deterministic model can exhibit complicated price dynamics, which help us to understand the underlying mechanism of the power-law behavior of the stochastic model. When there is no trader who switch between the two strategies, the model developed in this paper reduces to the no-switching model in $\mathrm{He}$ and Li (2015). We refer the reader to Dieci et al. (2006) for the complex price dynamics and He and $\mathrm{Li}(2007,2015)$ for a detailed discussion on the mechanism.

\section{Estimation of the Power-LaW Behavior IN THE DAX 30}

For the no-switching model, by model estimating, He and Li (2015) show that the autocorrelations (of returns, absolute returns and squared returns) of the market fraction model share the same pattern as those of the DAX 30. By conducting econometric analysis via Monte Carlo simulations, He and Li (2015) characterize these power-law behaviors and find that estimates of the power-law decay indices, the (FI)GARCH parameters, and the tail index of the estimated market fraction model closely match those of the DAX 30. The results strongly support the explanatory power of the heterogeneous agents models. For the extended model (2.7)-(2.12) with both fixed and switching traders, we are interested in the explanatory power of the adaptive behavior of investors in financial markets. We follow the same estimation procedure as in $\mathrm{He}$ and $\mathrm{Li} \mathrm{(2015)} \mathrm{and} \mathrm{show} \mathrm{that} \mathrm{the} \mathrm{model} \mathrm{with} \mathrm{the} \mathrm{switching} \mathrm{is} \mathrm{also} \mathrm{able} \mathrm{to} \mathrm{explain} \mathrm{the} \mathrm{power-law}$ behavior of the DAX 30. The finding provides a strong evidence on the rational switching and adaptive behavior in financial markets.

After a brief discussion of the stylized facts of the DAX 30, including both fat tail and powerlaw behavior, we introduce the calibration procedure to match the autocorrelation patterns in the

\footnotetext{
${ }^{11}$ The specification of the fundamental price process in (2.12) is to make sure that there is no significant ACs in returns, absolute returns and squared returns in the fundamental price. Since the focus of the paper is on the characteristics of returns, we also choose the fundamental price process $p_{t}^{*}$ defined in equation (2.12) to have an expected mean return of zero. In general, the fundamental value is calculated from the dividend. For simplicity we assume $p_{t}^{*}=K D_{t} / r$ here. Therefore we can impose the same random process (2.12) on the dividend, which is equivalent to (2.12) on the fundamental price. The long-run fundamental value $p^{*}=(K \bar{D}) / r$ defined in Footnote 9 only indicates a reference long-run fundamental value, which is chosen as the initial value of the fundamental price process.
} 
returns, absolute and squared returns for the DAX 30, present the calibration result and conduct an out-of-sample test. Based on the calibrated parameters for the model, we use Monte Carlo simulations to examine the effectiveness of the calibration in generating the autocorrelation patterns and estimating the decay indices of the power-law behavior, comparing with those of the DAX 30. We also use the calibration result to examine the power-law tail behavior of the model comparing with the DAX 30 . We show that the calibrated model closely generates the characterization of the power-law behavior of the DAX 30 in the return autocorrelation and tails.

As in $\mathrm{He}$ and $\mathrm{Li}$ (2015), the price index data for the DAX 30 comes from Datastream, which contains 8001 daily observations from 11 August, 1975 to 29 June, 2007. We use $p_{t}$ to denote the price index for the DAX 30 at time $t(t=0, \ldots, 8000)$ with log returns $r_{t}$ defined by $r_{t}=\ln p_{t}-\ln p_{t-1}(t=1, \cdots, 8000)^{12}$. The summary statistics of $r_{t}$ for the DAX 30 show high kurtosis and fat tails in $r_{t}$, suggesting that $r_{t}$ is not normally distributed. The returns are also showing volatility clusterings and time-varying market volatility. In addition, the returns contain little serial correlation, but the absolute returns $\left|r_{t}\right|$ and the squared returns $r_{t}^{2}$ do have significantly positive and slow decaying serial correlation over long lags. This indicates the long-range dependence or the power-law behavior in volatility for the DAX $30 .{ }^{13}$

3.1. Model Calibration and Result. As in $\mathrm{He}$ and Li (2015), to calibrate the power-law behavior of the DAX 30 to our model, we minimize the average distance between the autocorrelations of the log returns, the squared log returns, and the absolute log returns of the DAX 30 and the corresponding autocorrelations generated from the models ${ }^{14}$. More precisely, denote $\Theta$ the parameter space of the model. Let $\theta \in \Theta$ be the vector of parameters in the model to be calibrated, $N$ be the number of independent simulations of the model, $\widehat{\beta}^{n}$ be the estimated autocorrelations of the $n$-th run of the model, and $\widehat{\beta}_{D A X}$ be that of the DAX 30 . In calibration, we solve

$$
\widehat{\theta} \in \arg \min _{\theta \in \Theta} D_{\theta}, \quad D_{\theta}:=\left\|\frac{1}{N} \sum_{n=1}^{N} \widehat{\beta}^{n}-\widehat{\beta}_{D A X}\right\|^{2}
$$

\footnotetext{
${ }^{12}$ Note that at daily frequency, the difference between log-returns and simple returns is very small.

${ }^{13} \mathrm{We}$ refer $\mathrm{He}$ and $\mathrm{Li}$ (2015) for the detailed statistics, time series and autocorrelation plots.

${ }^{14}$ Note that we do not consider other moments such as scales of returns and absolute returns and others. By exclusively focusing on the autocorrelations of return, squared return and absolute return, we provide a simple way to gain insight into the generating mechanism of power-law behavior of volatility of the model.
} 
for the standard Euclidian norm $\|\cdot\|$, using an asynchronous parallel pattern search algorithm. ${ }^{15}$ The parameters in the model are chosen to lie in the following ranges: ${ }^{16} \alpha \in[0,1]$, $\gamma \in[0.05,5.5], a_{1}, a_{2} \in[0.001,9.0], \mu \in[0.1,5], m_{0} \in[-1,1], n_{0} \in[0.05,0.995], \delta \in[0,1]$, $b \in[0.05,8.5], \beta \in[0.5,1.5], \sigma_{\varepsilon} \in[0.005,0.05], \sigma=\sqrt{K} \sigma_{\varepsilon}$ and $\sigma_{\delta} \in[0.05,8.5]$. However $p_{0}^{*}=p^{*}=100, q=r^{2}$, and $r=0.05$ are kept fixed. In the calibration and the subsequent econometric analysis, we ran 1,000 independent simulations over 9,000 time periods and discarded the first 1,000 time periods to wash out possible initial noise effect. For each run of the model we obtain 8,000 observations to match the sample size of the DAX 30. It is not possible to use autocorrelations at all lags, so we focus on all lags until 50 and then each fifth lag up to $100^{17}$. This corresponds to 60 autocorrelations in total for return, the absolute return and squared return, respectively. Essentially, with 60 autocorrelations estimated for each of the $r_{t}$, $r_{t}^{2}$ and $\left|r_{t}\right|$, the dimension of $\widehat{\beta}^{n}$ and $\widehat{\beta}_{D A X}$ is 180 in total. The calibrated parameters of the model are reported in Table 3.1. ${ }^{18}$

TABLE 3.1. The calibrated parameters of the models

\begin{tabular}{cccccccccccc}
\hline$\alpha$ & $\gamma$ & $a_{1}$ & $a_{2}$ & $\mu$ & $n_{0}$ & $m_{0}$ & $\delta$ & $b$ & $\sigma$ & $\sigma_{\delta}$ & $\beta$ \\
\hline 0.488 & 1.978 & 7.298 & 0.320 & 1.866 & 0.313 & -0.024 & 0.983 & 3.537 & 0.231 & 3.205 & 0.954 \\
\hline
\end{tabular}

We now provide an economic intuition of the calibrated result. Based on the calibrated parameters in Table 3.1, parameter $n_{o}=0.313$ implies that, among two strategies, there are some (about $31 \%$ ) traders who do not change their investment strategies and many (about 69\%) traders switch between two strategies with a switching intensity measured by $\beta=0.954$. This

\footnotetext{
${ }^{15}$ The software implementing the algorithm is APPSPACK 5.01, see more details in Gray and Kolda (2006), Griffin and Kolda (2006), and Kolda (2005). In the implementation, to avoid possible local minima we tried different set of starting values, and for each set of starting value we search for the minimum and then we re-initialize and search for the new minimum again. We repeat the procedure until there's no further improvements.

${ }^{16}$ The parameter ranges for $\alpha, m_{0}, n_{o}, \delta$ are implied by the model specifications. The ranges for parameters $\gamma, a_{1}, a_{2}$ and $\mu$ are selected to reflect reasonable behavior of the traders based on the analysis of the underlying deterministic model in Dieci et al. (2006). The range for $\sigma_{\epsilon}$ represents the volatility of the fundamental price, while the range for $\sigma_{\delta}$ indicates the daily market price volatility level.

${ }^{17}$ We choose a large numbers of lags of ACs because our method of calibration of the model is exclusively focused on the ACs, and it works well to produce reasonable results reported in Fig. 3.1. In practice, much less lags may contain the same information and too many lags would waste computation time and even affect the accuracy of estimation, see for instance, Franke and Westerhoff (2012) for related discussion.

${ }^{18}$ It is likely that the estimated parameter values can be different for differ indices over different time periods. In fact, in our earlier exploratory model ( $\mathrm{He}$ and $\mathrm{Li}, 2007,2008,2015$ and $\mathrm{Li}$ et al., 2010) using other indices or different periods of an index, the estimated model parameters are different in each of the cases. Quantitatively the stylized facts can vary over time, however, qualitatively the main feature of the stylized facts remains the same over long time periods and across different markets. It is this qualitative feature of the long memory pattern and the generating mechanism provided in Section 4.1 that this paper contributes to the current literature. It is from this perspective that the model estimation in this paper is robust.
} 
is consistent with the empirical evidence of using fundamental and technical analysis and the adaptive behavior of investors. With $m_{o}=-0.024$, it indicates that, among those traders who do not change their investment strategies, there are about equal numbers of trend followers and fundamentalists. This result is different from the estimation of the market fraction model of $\mathrm{He}$ and $\mathrm{Li}(2015)$ and the dominance of the trend followers without switching. These results demonstrate that both fundamentalists and trend followers are active in the market and the market is populated with confident traders as well as adaptive traders. This is in line with the findings from foreign exchange markets in Allen and Taylor (1990) and Taylor and Allen (1992) and fund managers in Menkhoff (2010). The relatively higher $a_{1}$ than $a_{2}$ implies that the fundamentalists are more risk averse than the trend followers ${ }^{19}$. A value of $\alpha=0.488$ indicates that the speed of price adjustment of the fundamentalists towards the fundamental value is indicated by $1 /(1-\alpha)$, which is about two trading periods. This may explain the frequent deviations of the market price from the fundamental value in the short-run but not in the longrun. A value of $\gamma=1.978$ indicates that trend followers extrapolate the price trend, measured by the difference between the current price and the geometric moving average of the history prices, actively. Also note that $\gamma=1.978>1$ does not lead to explosive expectations by trend followers because of the quadratic volatility function in the denominator of the demand function. The geometric decay rate $\delta=0.983$ indicates a slow decaying weight. The parameter $b_{2}=b \sigma_{1}^{2}$ measures the influence of the sample variance $v_{t}$, in addition to the common belief on the price volatility $\sigma_{1}^{2}$, to the estimated price volatility for trend followers. The value of $b=3.537$ implies that trend followers are cautious when estimating the price volatility, though they are less risk averse. The annual return volatility of $\sigma=23.1 \%$ is close to the annual return volatility of $19.67 \%(=\sqrt{250} \times 0.01244)$ for the DAX 30. A value of $\mu=1.866$ indicates that the market maker actively adjusts the market price to the excess demand of the traders. A positive $\sigma_{\delta}$ indicates that the noise traders are active in the market. In summary, the calibrated parameters show that the market is dominated by traders who switch between the two strategies based on their performance over the time, although there are some traders who do not change

\footnotetext{
${ }^{19}$ Note that for simplicity, we assume that agents' risk preferences switch when their strategies switch. Comparing to the trend followers who invest in short-run and are less risk averse, the fundamentalists invest in long-run and are more risk averse in general. We see from Footnote 9 that trend followers have a systematically higher variance estimate relative to the fundamentalists (by $b v_{t} \sigma_{1}^{2}$ ). When the additional term is much larger than $\left(1+r^{2}\right) \sigma_{1}^{2}$, the trend followers have much higher risk perception which also justifies the relative lower risk aversion of the trend followers than the fundamentalists.
} 
their strategies over the time. Due to the switching, the market becomes more volatile, which supports the theoretical predication in Brock and Hommes (1998).

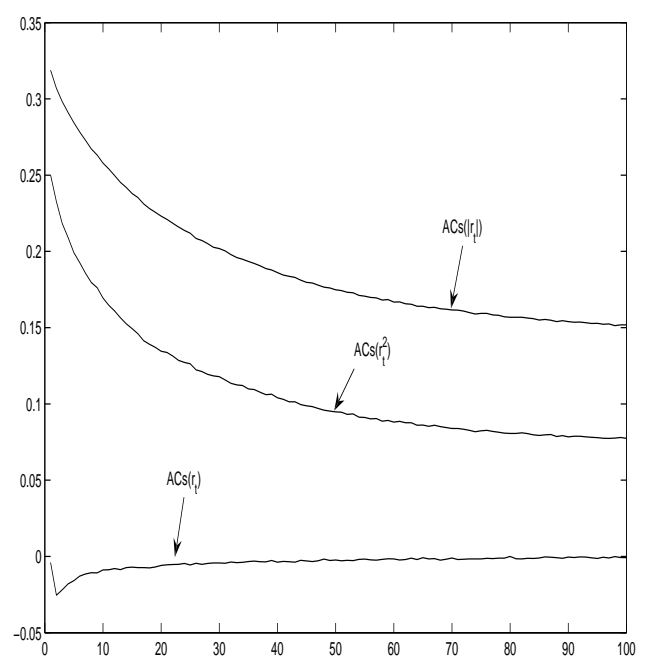

(a)
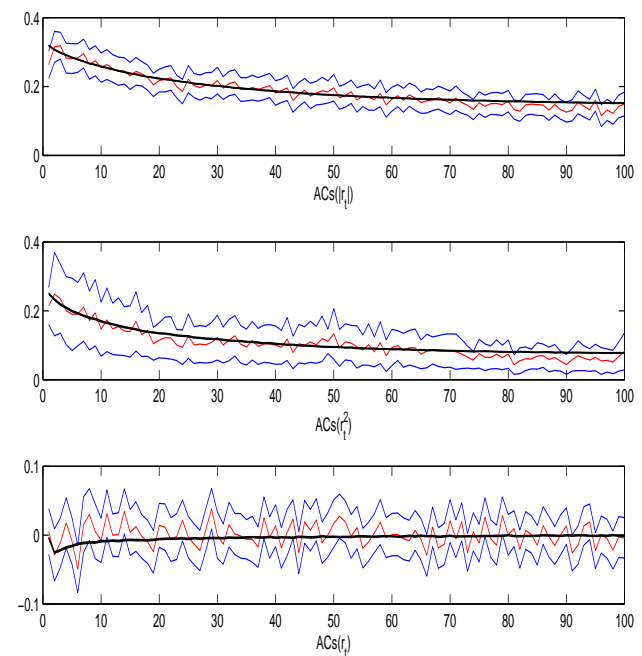

(b)

FIGURE 3.1. (a) Autocorrelations of $r_{t}, r_{t}^{2}$ and $\left|r_{t}\right|$ for the model. (b) The ACs of the returns, the squared returns and the absolute returns for the calibrated model and the DAX 30. The smooth lines refer to the model while the $95 \%$ confidence intervals are those for the DAX 30.

\subsection{The Autocorrelation Patterns of the Calibrated Model and Out-of-Sample Test. As}

in He and Li (2015), we want to know if the calibrated model is able to replicate the powerlaw behavior of the DAX 30. Using the parameters in Table 3.1, we run 1,000 independent simulations for the model and report the average ACs for returns, squared returns and absolute returns. The resulting ACs plots in Fig. 3.1(a) show insignificant ACs for the returns, but significantly positive and slowly decaying ACs over long lags for $r_{t}^{2}$ and $\left|r_{t}\right|$, very similar AC patterns to the DAX 30. Further, the sample autocorrelations for the absolute returns are greater than that for the squared returns at all lags up to at least 100 lags. Fig. 3.1(b) plots the ACs of returns, the squared returns and the absolute returns for the model together with the DAX 30 respectively. For comparison, we use the Newey-West corrected standard error and plot the corresponding $95 \%$ confidence intervals of the ACs of the DAX 30, showing that all of the ACs of the model lie inside the confidence intervals of the DAX 30.

Different from $\mathrm{He}$ and $\mathrm{Li}$ (2015), here we perform an out-of-sample test to evaluate the performance of the model. Recall that we calibrate the model using the DAX 30 daily price index from 11 August 1975 to 29 June 2007, we now use data from 02 July 2007 to 02 April 
2015 and plot ACs for returns, squared returns and absolute returns of the DAX 30 together with their 95\% confidence intervals in Fig. 3.2. It shows that the ACs of returns and squared returns of the calibrated model fit in the $95 \%$ confidence intervals of the DAX 30 reasonably well, but the ACs of absolute returns of the calibrated model lie outside of the corresponding confidence intervals of the DAX 30 after lag 30, which indicates that the persistence in volatility of the DAX 30 is not as strong as before since the global financial crisis. Overall, the out-of-sample result indicates that the model performs reasonably well out of the sample and the calibration method effectively captures the ACs patterns of the DAX 30.
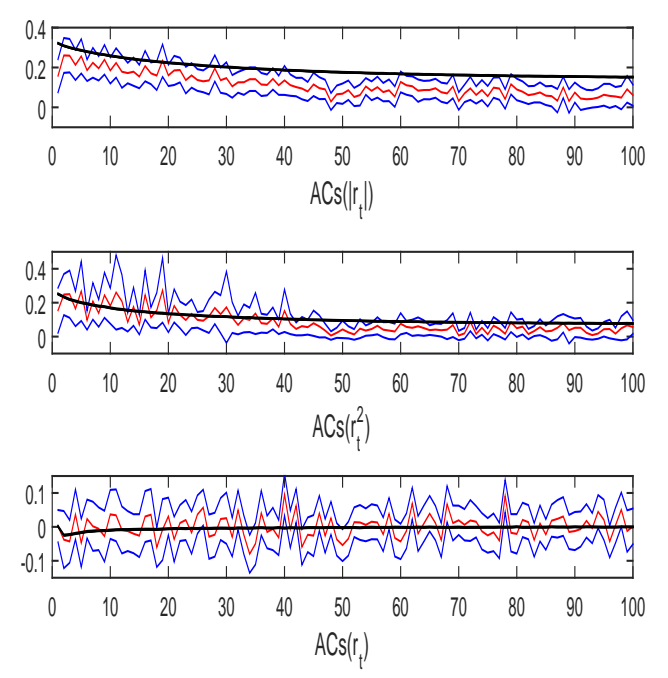

FIGURE 3.2. The ACs of the returns, the squared returns and the absolute returns for the calibrated model and the DAX 30. The smooth lines refer to the model while the $95 \%$ confidence intervals are those for the DAX 30 from 02 July 2007 to 02 April 2015.

Based on the calibrated parameters for the model, we use Monte Carlo simulations to further examine the effectiveness of the calibration in estimating the decay indices of the power-law behavior of ACs and in volatility clustering, comparing with those of the DAX 30. We also use the calibration result to examine the power-law tail behavior of the model comparing with the DAX 30. The results show that the calibrated model closely generates the characterization of the power-law behavior of the DAX 30 in the return autocorrelation, volatility clustering and tails. $^{20}$

3.3. A Comparison Test. To see how well the model is able to describe the characteristics in the DAX 30, we follow He and Li (2015) and conduct the Wald test to see if the estimates based

\footnotetext{
${ }^{20}$ Since the results are consistent with the findings in $\mathrm{He}$ and $\mathrm{Li}$ (2015), we do not report them in details.
} 
upon the calibrated model equal to those of the DAX 30. In other words, for decay index $d$ we test the hypothesis

$$
H_{0}: d_{D A X}=d
$$

using the Wald test statistic given by

$$
W=\left(\hat{d}_{D A X}-\hat{d}\right)^{2} / \hat{\Sigma}
$$

where $\hat{\Sigma}$ is simply the variance of $\hat{d}_{D A X}$. The resulting test statistics are summarized in Table 3.2. In the column ' $r_{t}$ ', the first sub-row reports the test statistics corresponding to $\hat{d}_{G P H}$, and the second sub-row corresponding to $\hat{d}_{R H},{ }^{21}$ and so on. Notice that the critical values of the Wald test at $5 \%$ and $1 \%$ significant levels are 3.842 and 6.635 , respectively. For the returns, we see that the estimated $d$ of the DAX 30 and the model are significantly different. However, for the squared returns and the absolute returns, the differences between the estimated $d$ of the DAX 30 and the model are not statistically significant. This result shows that the calibrated model is able to describe the ACs of the absolute and squared returns in the DAX 30.

TABLE 3.2. The Wald test of $d$ with $m=50,100,150,200,250$

\begin{tabular}{c|ccccc}
\hline$m$ & 50 & 100 & 150 & 200 & 250 \\
\hline \multirow{2}{*}{$r_{t}$} & 19.41 & 45.62 & 61.94 & 65.86 & 76.35 \\
& 35.41 & 92.24 & 126.0 & 117.5 & 129.4 \\
\hline \multirow{2}{*}{$r_{t}^{2}$} & 0.071 & 1.309 & 0.282 & 0.036 & 0.023 \\
& 0.037 & 1.246 & 0.050 & 0.767 & 0.276 \\
\hline \multirow{2}{*}{$\left|r_{t}\right|$} & 0.116 & 1.165 & 1.672 & 0.413 & 0.195 \\
& 0.020 & 0.350 & 0.067 & 0.031 & 0.015 \\
\hline
\end{tabular}

\section{Mechanism Explanation of the Calibration Results}

We have shown that the calibrated model closely matches the stylized facts of the DAX 30. In this section, we explore the explanation on the generating mechanism of the power-law behavior.

There are several explanatory mechanisms on volatility clustering based on the underlying deterministic dynamics in HAM literature. ${ }^{22}$ The first one is based on the local stability and

$\overline{ }^{21} \hat{d}_{G P H}$ and $\hat{d}_{R H}$ are two semiparametric estimators of the power-law decay index of autocorrelations depending on bandwidth $m$, see $\mathrm{He}$ and $\mathrm{Li}$ (2015) for detailed discussions.

${ }^{22}$ Different from the mechanisms based on the deterministic dynamics, there are also other mechanisms on volatility clustering based on stochastic herding or stochastic demand (Alfarano et al. (2005) and Franke and Westerhoff (2011)). 


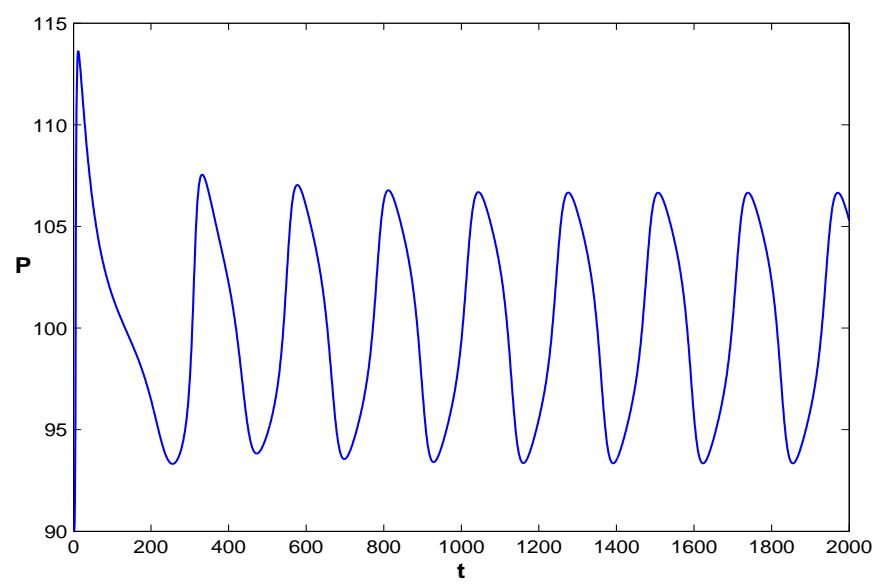

FIGURE 4.1. The price of the deterministic model with the calibrated parameters.

Hopf bifurcation, explored in He and Li (2007). Essentially, on the parameter space of the deterministic model, near the Hopf bifurcation boundary, the fundamental price can be locally stable but globally unstable, depending on the initial values. Due to the nature of Hopf bifurcation, such instability leads to periodic oscillations around the fundamental price. Then triggered by fundamental noise and market noise, $\mathrm{He}$ and $\mathrm{Li}$ (2007) find that the interaction of fundamentalists, risk-adjusted trend chasing from the trend followers and the interplay of the noises and the underlying deterministic dynamics can be the source of power-law behavior.

The second mechanism proposed in Gaunersdorfer et al. (2008) is characterized by the coexistence of two locally stable attractors with different size. The interaction of the coexistence of the deterministic dynamics and noise processes can then trigger the switching among the two attractors and endogenously generate volatility clustering. Dieci et al. (2006) show that the model developed in this paper can display such co-existence of locally stable fundamental price and periodic cycle. More recently, He, Li and Wang (2015) further verify this endogenous mechanism on volatility clustering of the model. Economically, they show that volatility clustering occurs when neither the fundamental nor trend following traders dominate the market and when traders switch more often between the two strategies.

Mathematically, the model in this paper shares the same underlying deterministic mechanism explored for a market fraction model without switching in $\mathrm{He}$ and $\mathrm{Li}$ (2007). For the corresponding deterministic model with the calibrated parameters, the constant fundamental equilibrium becomes unstable, leading to (a)periodical oscillation of the market price around the fundamental equilibrium, illustrated in Fig. 4.1. Triggered by the random noises, such 
periodical deviations of the price from the fundamental value in the deterministic model are inherited in the stochastic model. Fig. 4.2(a) plots the time series of typical market price and fundamental price of the stochastic model. It shows that the price deviates from the fundamental price from time to time, but in general, follows the fundamental price. In addition, the returns of the stochastic model display the stylized facts of volatility clustering in Fig. 4.2(b) and nonnormality of return distribution in Fig. 4.2(c). Furthermore, with the two noise processes, Fig. 4.2(d) demonstrates insignificant ACs for the returns, while Figs 4.2(e) and (f) show significant and decaying ACs in the absolute and squared returns, respectively. ${ }^{23}$ They clearly demonstrate that, for the calibrated model, noise traders play an important role in the generation of insignificant ACs on the returns, while the significant decaying AC patterns of the absolute returns and squared returns are more influenced by the noisy fundamental process. These results are consistent with He and Li (2007, 2015), and Chiarella, He and Hommes (2006).

Economically, this paper provides a different behavioral mechanism from He and Li (2015). In $\mathrm{He}$ and $\mathrm{Li}$ (2015), a constant market fraction model is used to examine the potential mechanism in generating power-law behavior in return autocorrelation patterns. The estimated parameters show that, with the dominance of trend followers (about 60\%), the model is able to match closely the power-law behavior of the DAX30. In this paper, the estimated parameters illustrate different trading behavior. Essentially, the market is dominated by these traders (about 70\%) who consistently switch between two strategies. It is traders' adaptive behavior that generates the power-law behavior.

Given the different behavioral mechanisms, we want to know which mechanism is better. Intuitively, with the flexibility of the model in this paper, we would expect the adaptive switching model, denoted SM, of this paper to fit the data better than the (no-switching) market fraction model, denoted MF, of He and Li (2015), and the pure-switching model, denoted PSM, with $n_{0}=0$ in line of Brock and Hommes (1998). In Appendix A, we provide the calibrated parameters in Tab. A.1, the ACs patterns in Fig. A.1, and the Wald test for the PSM, which share the similar results and implications to the SM. We calculate the distances of ACs, the $D_{\widehat{\theta}}$ in Eq. (3.1), between the DAX 30 and the SM, PSM, and MF models and obtain 4.56 and 4.59 and

\footnotetext{
${ }^{23} \mathrm{We}$ also plot the times series of price, fundamental value, returns, return distribution, the ACs of return, absolute and squared returns with one noise, either the fundamental noise in Fig. B.1 or market noise in Fig. B.2, respectively, in Appendix B.
} 


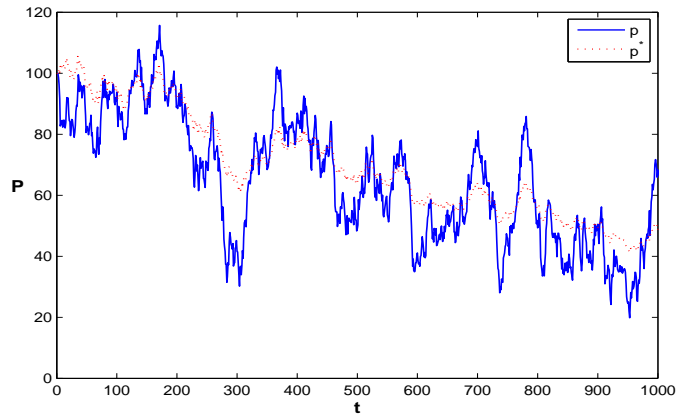

(a) The price and the fundamental price

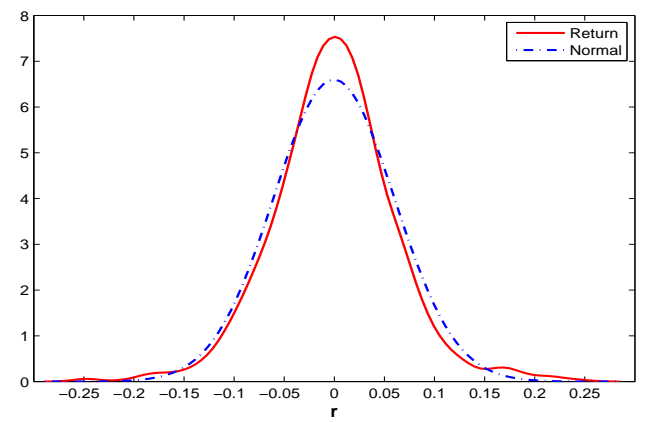

(c) The density of the return

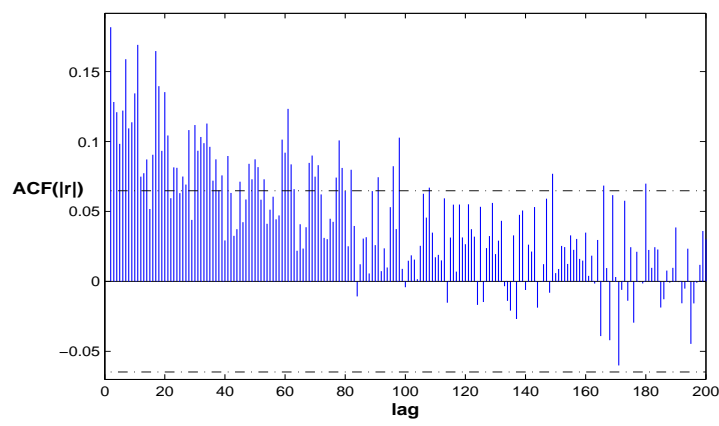

(e) The ACs of the absolute return

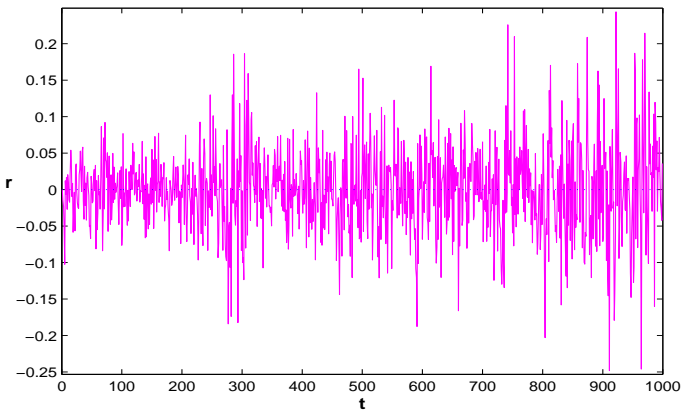

(b) The return $(r)$

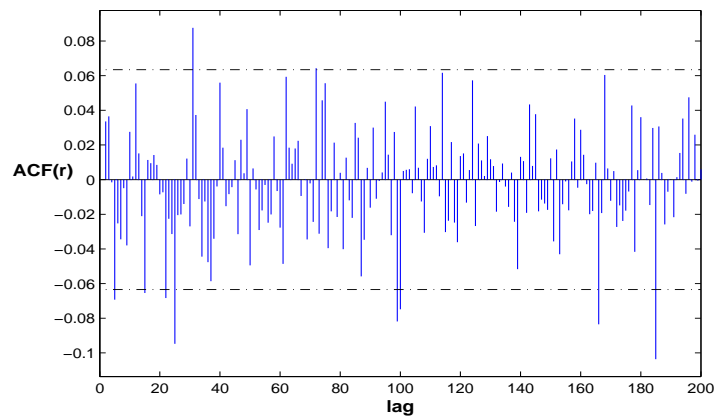

(d) The ACs of the return

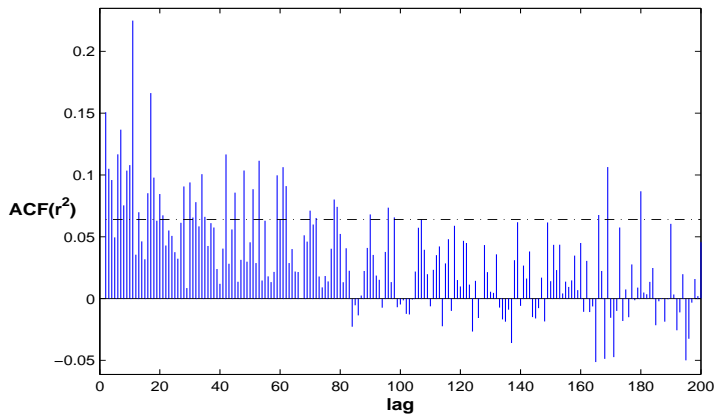

(f) The ACs of the squared return

FIGURE 4.2. The time series of (a) the price (red solid line) and the fundamental price (blue dot line) and (b) the return; (c) the return density distribution; the ACs of (d) the returns; (e) the absolute returns, and (f) the squared returns.

4.63 respectively. The test statistics ${ }^{24}$ are 106,108 , and 112 , respectively. These results seems to confirm that the SM performs better than the PSM and MF models in terms of minimizing the distance in Eq. (3.1) and the weighted average distance by taking into account the $\hat{\Omega}$. However, we would like to emphasize that the comparison is based upon the magnitudes of distances we use. In other words, this is not to say that 4.56 (106) is significantly lower than 4.59 (108) and

\footnotetext{
${ }^{24}$ The test statistics $\left(\hat{\beta}_{D A X}-\hat{\beta}\right)^{\prime} \hat{\Omega}^{-1}\left(\hat{\beta}_{D A X}-\hat{\beta}\right)$ follows a Chi-square distribution with critical value 180 at the $5 \%$ significant level, where $\hat{\beta}$ is estimated from the simulation model and $\hat{\Omega}^{-1}$ is the generalized inverse (see, for example, Cameron and Trivedi, 2005) of corresponding covariance matrix, for ACs up to 50 lags for the return, the squared return and the absolute return of the SM and PSM
} 
4.63 (112). ${ }^{25}$ A formal procedure such as that suggested by Hnatkovska et al., (2012) might be explored further. ${ }^{26}$

\section{CONCLUSION}

Theoretically oriented HAMs have provided many insights into market behavior such as market booming and crashing, multiple market equilibrium, short-run deviation of market price from the fundamental price and long-run convergence of the market price to the fundamental price. Combined with numerical simulations, the HAMs are able to reproduce some stylized fact, such as non-normality in return and volatility clustering. More recent developments in HAMs have stimulated many interests in the generation mechanism of those stylized facts and in particular, power-law behavior. However, estimation and calibration of HAMs, in particular the switching models, to the power-law behavior of financial data, together with some mechanism explanation and economic intuition, are still a difficult and challenging task.

This paper calibrates an extended switching HAM to characterize the power-law behavior in the DAX 30. The model considers a market populated by heterogeneous traders who use either fundamental or chartist strategies. The market fractions of traders who use the two strategies have both fixed and switching components. The calibration method is based on minimization of the average distance between the autocorrelations (ACs) of the returns, the squared returns and the absolute returns of the DAX 30 and the corresponding ACs generated from the model. With the parameter values of the calibrated model, we show that the calibrated model matches closely to the corresponding estimates for the DAX 30 and generates most of the stylized facts observed in the DAX 30.

The calibration results support the empirical evidence in financial markets that investors and fund managers use combinations of fixed and switching strategies based on various fundamental and technical analysis when making complicated investment decisions. By calibrating the model to the daily DAX 30 index from 1975 to 2007, we show that the market is dominated

\footnotetext{
${ }^{25}$ We would like to thank one of the referees who pointed this out.

${ }^{26}$ It is possible to develop measures of goodness of fit. While the measures of goodness of fit are very useful when comparing the performance of different HAMs (see, for example, Franke and Westerhoff, 2012), the comparison results on various econometric characterizations between HAM and the actual data seem to imply that it might be difficult to get meaningful test statistics. In our approach the sampling error from the actual data is dealt with the confidence intervals of the estimates and that from the simulation data is eliminated by running many independent simulation. For a more general discussion on the comparison of the simulation models with the real world data, see Li et al. (2006, 2010).
} 
by the adaptive investors who constantly switch between the fundamental and trend following strategies, though there are some investors who never change their strategies over the time. In addition, the calibrated model also provides a different behavioral explanation on the generating mechanism of the power-law behavior in the literature. In conclusion, the calibration results provide strong support to the explanatory power of heterogeneous agent models and the empirical evidence of heterogeneity and bounded rationality. 
APPENDiX A. ECONOMETRIC ANALYSis OF THE PURE SWITCHING MODEL

This Appendix provides calibration results of the pure switching model (2.7)-(2.12) with $n_{o}=0$ to characterize the power-law behavior of the DAX 30 .

TABLE A.1. The calibrated parameters of the SW models

\begin{tabular}{cccccccccc}
\hline$\alpha$ & $\gamma$ & $a_{1}$ & $a_{2}$ & $\mu$ & $\delta$ & $b$ & $\sigma$ & $\sigma_{\delta}$ & $\beta$ \\
\hline 0.513 & 0.764 & 7.972 & 0.231 & 2.004 & 0.983 & 3.692 & 0.231 & 3.268 & 0.745 \\
\hline
\end{tabular}

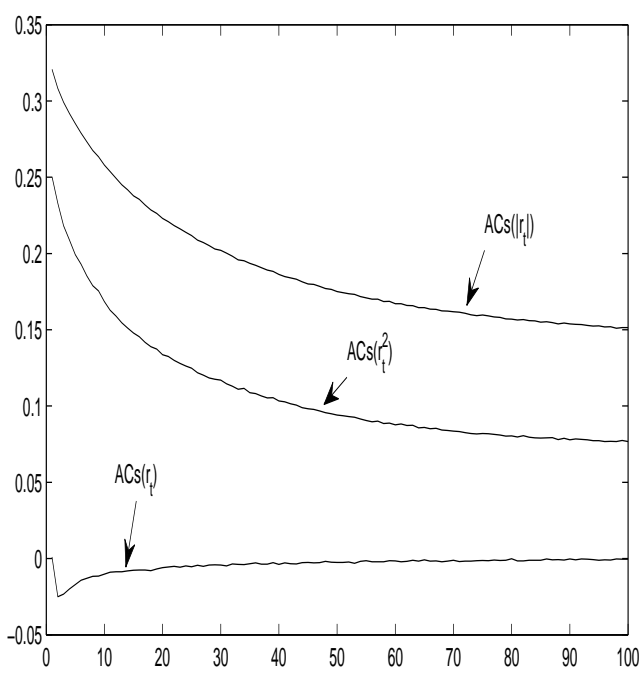

(a)
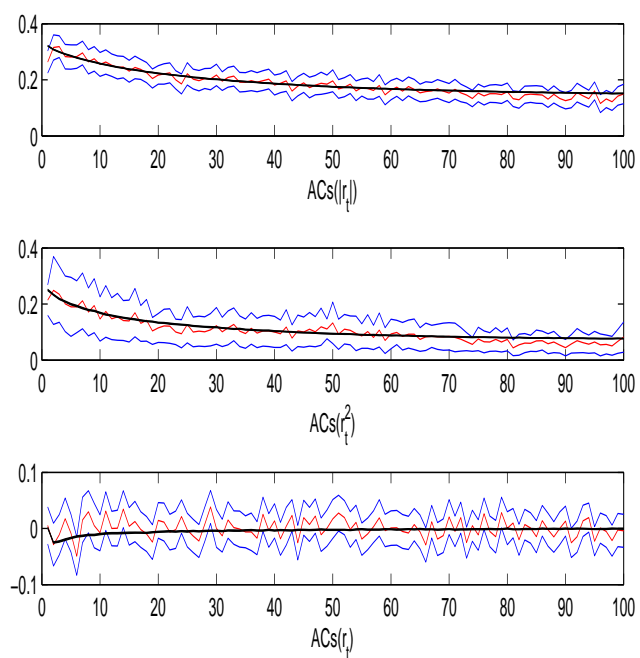

(b)

FIGURE A.1. (a) Autocorrelations of $r_{t}, r_{t}^{2}$ and $\left|r_{t}\right|$ for the SW model. (b) The ACs of the returns, the squared returns and the absolute returns for the calibrated SW model and the DAX 30. The smooth lines refer to the SW model while the 95\% confidence intervals are those for the DAX 30.

TABLE A.2. The Wald test of $d$ with $m=50,100,150,200,250$

\begin{tabular}{c|ccccc}
\hline$m$ & 50 & 100 & 150 & 200 & 250 \\
\hline \multirow{2}{*}{$r_{t}$} & 18.92 & 44.73 & 61.61 & 66.17 & 77.30 \\
& 34.99 & 91.16 & 125.7 & 118.6 & 132.0 \\
\hline \multirow{2}{*}{$r_{t}^{2}$} & 0.068 & 1.247 & 0.263 & 0.034 & 0.026 \\
& 0.035 & 1.272 & 0.038 & 0.694 & 0.234 \\
\hline \multirow{2}{*}{$\left|r_{t}\right|$} & 0.105 & 1.085 & 1.603 & 0.413 & 0.198 \\
& 0.024 & 0.331 & 0.064 & 0.031 & 0.016 \\
\hline
\end{tabular}




\section{Appendix B. The EFfect of One Noise}

This appendix demonstrates the impact of single noise in the model (2.7)-(2.12) on the AC patterns of the return, absolute returns and squared returns.

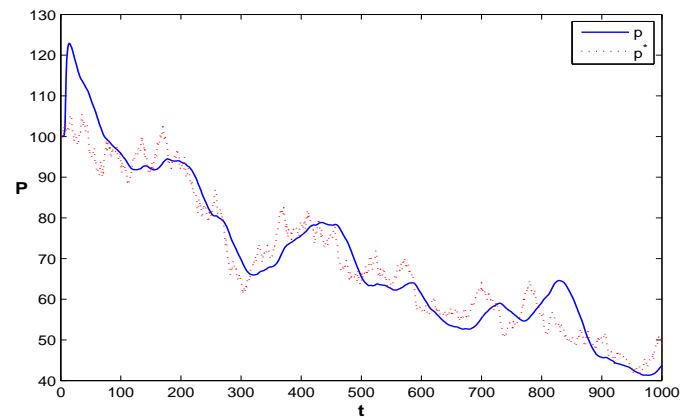

(a) The price and the fundamental price

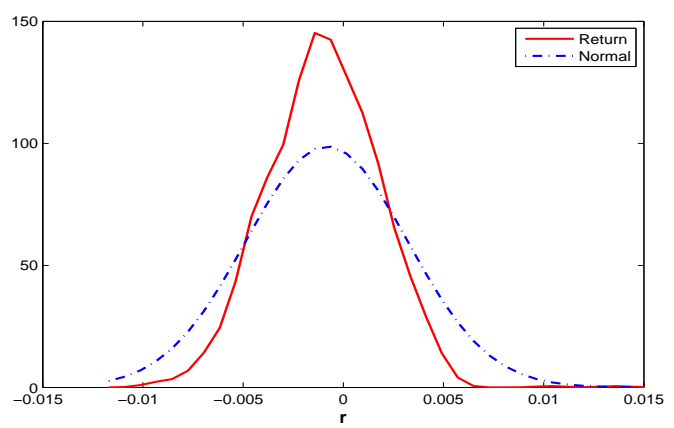

(c) The density of the return

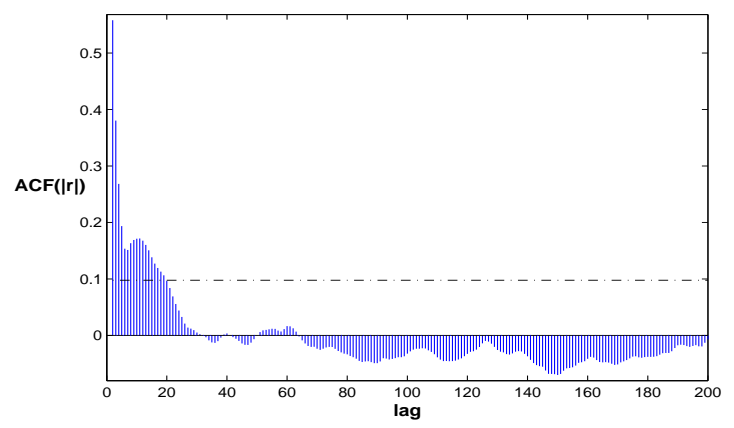

(e) The ACs of the absolute return

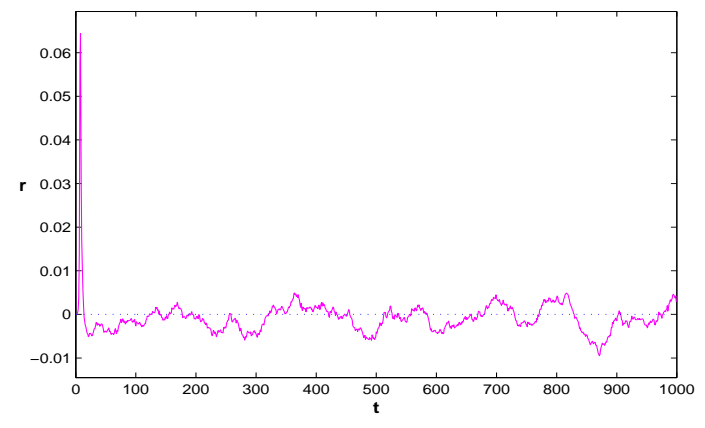

(b) The return $(r)$

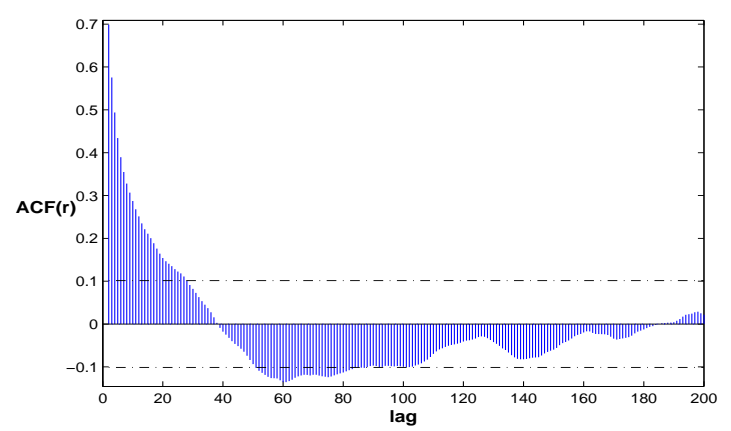

(d) The ACs of the return

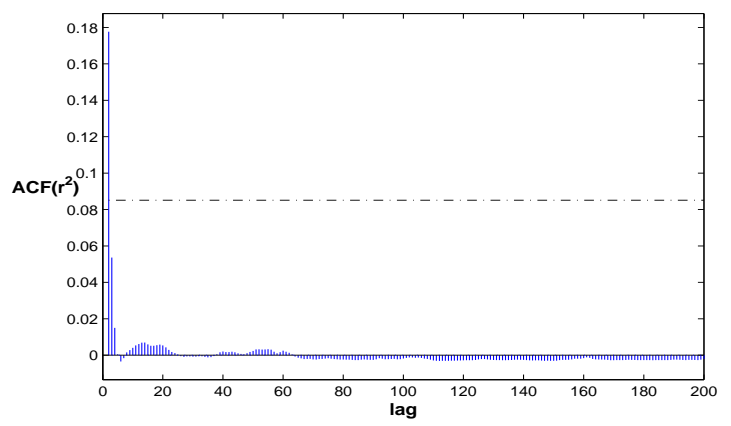

(f) The ACs of the squared return

FIGURE B.1. The time series of (a) the price (red solid line) and the fundamental price (blue dot line) and (b) the return; (c) the density distribution of the returns; the ACs of (d) the returns; (e) the absolute returns, and (f) the squared returns, with the fundamental noise only $\left(\sigma_{\delta}=0\right)$. 


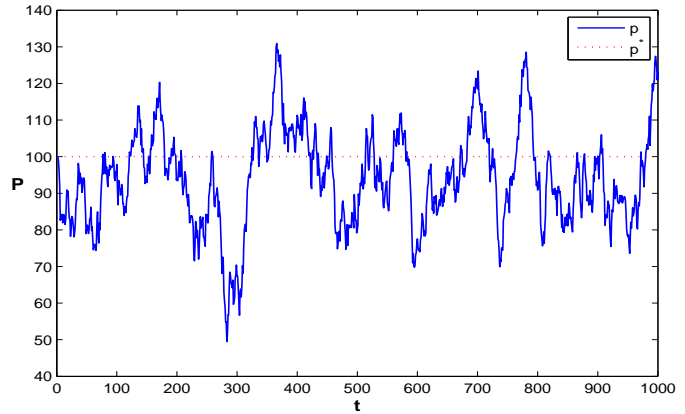

(a) The price and the fundamental price

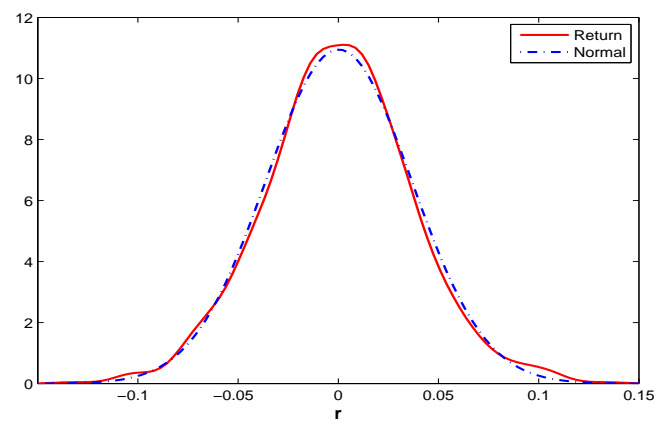

(c) The density of the return

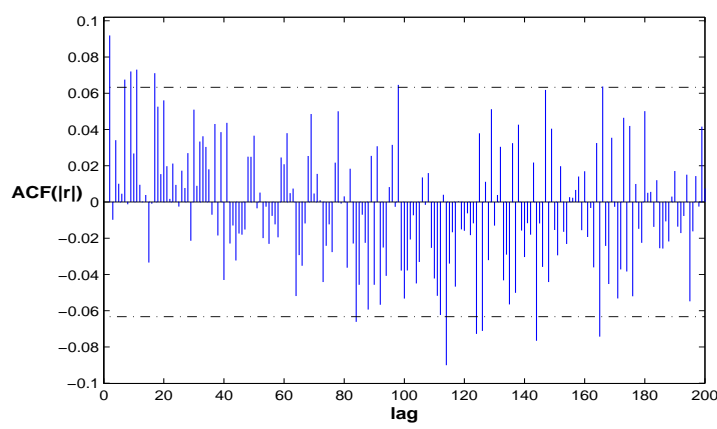

(e) The ACs of the absolute return

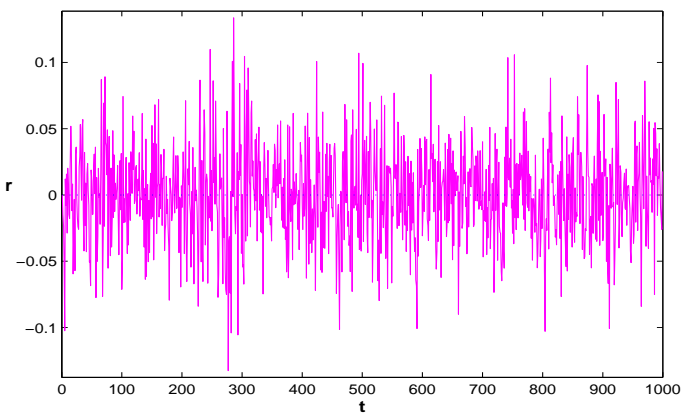

(b) The return $(r)$

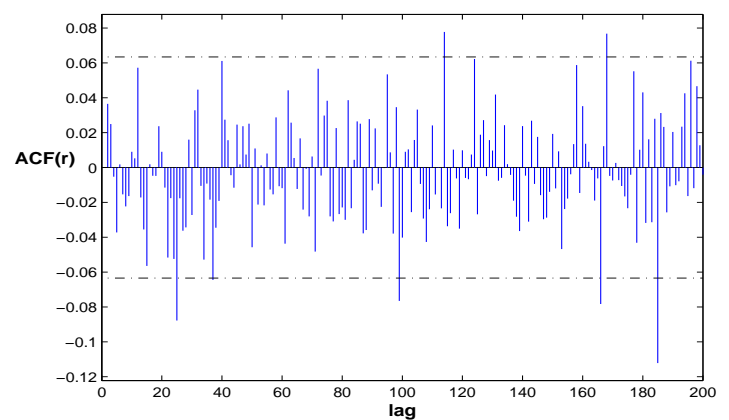

(d) The ACs of the return

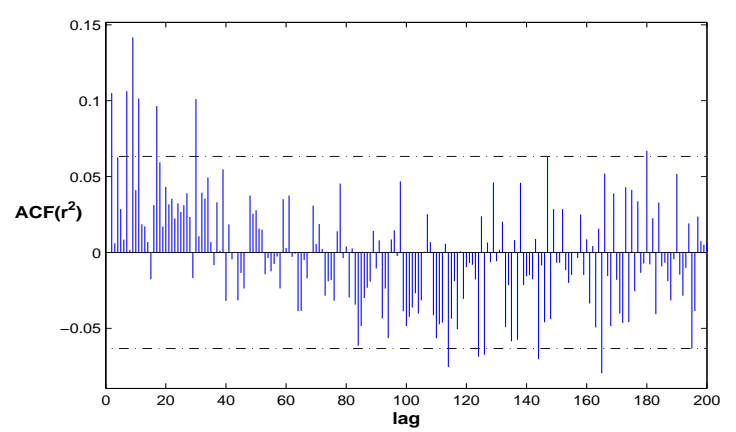

(f) The ACs of the squared return

FIGURE B.2. The time series of (a) the t price (red solid line) and the fundamental price (blue dot line) and (b) the return; (c) the density distribution of the returns; the ACs of (d) the returns; (e) the absolute returns, and (f) the squared returns, with the market noise only $\left(\sigma_{\epsilon}=0\right)$. 


\section{REFERENCES}

Alfarano, S., Lux, T. and Wagner, F. (2005), 'Estimation of agent-based models: the case of an asymmetric herding model', Computational Economics 26, 19-49.

Allen, H. and Taylor, M. (1990), 'Charts, noise and fundamentals in the London foreign exvhange market', Economic Journal 100, 49-59. Conference.

Amilon, H. (2008), 'Estimation of an adaptive stock market model with heterogeneous agents', Journal of Empirical Finance 15, 342-362.

Anufriev, M., and Hommes, C. (2012), 'Evolutionary selection of individual expectations and aggregate outcomes', American Economic Journal - Micro 4, 35-64.

Baak, S. (1999), 'Test for bounded rationality with a linear dynamics model distorted by heterogeneous expectations', Journal of Economic Dynamics and Control 23, 1517-1543.

Boswijk, H., Hommes, C. and Manzan, S. (2007), 'Behavioral heterogeneity in stock prices', Journal of Economic Dynamics and Control 31, 1938-1970.

Brock, W. and Hommes, C. (1997), 'A rational route to randomness', Econometrica 65, 1059-1095.

Brock, W. and Hommes, C. (1998), 'Heterogeneous beliefs and routes to chaos in a simple asset pricing model', Journal of Economic Dynamics and Control 22, 1235-1274.

Cameron, A. and Trivedi, P. (2005), Microeconometrics: Methods and Applications, Cambridge University Press.

Chavas, J. (2000), 'On the information and market dynamics: The case of the U.S. beef market', Journal of Economic Dynamics and Control 24, 833-853.

Chen, S.-H., Chang, C.-L. and Du, Y.-R. (2012), 'Agent-based economic models and econometrics', Knowledge Engineering Review 27, 187-219.

Chen, S.-H. and Yeh, C.-H. (2002), 'On the emergent properties of artificial stock markets: the efficient market hypothesis and the rational expectations hypothesis', Journal of Economic Behavior and Organization 49, 217-239.

Cheung, Y.-W., Chinn, M. and Marxh, I. (2004), 'How do UK-based foreign exchange dealers think their market operates?', International Journal of Finance and Economics 9, 289-306.

Chiarella, C. (1992), 'The dynamics of speculative behaviour', Annals of Operations Research 37, 101-123.

Chiarella, C., Dieci, R. and Gardini, L. (2002), 'Speculative behaviour and complex asset price dynamics: a global analysis', Journal of Economic Behavior and Organization 49, 173-197.

Chiarella, C., Dieci, R. and He, X. (2009), Heterogeneity, market mechanisms and asset price dynamics, in T. Hens and K. Schenk-Hoppe, eds, 'Handbook of Financial Markets: Dynamics and Evolution', North-Holland, Elsevier, pp. 277-344.

Chiarella, C. and He, X. (2002), 'An adaptive model on asset pricing and wealth dynamics with heterogeneous trading strategies', Quantitative Finance Research Center, University of Techonology, Sydney. Working Paper No. 84.

Chiarella, C. and He, X. (2003), 'Heterogeneous beliefs, risk and learning in a simple asset pricing model with a market maker', Macroeconomic Dynamics 7, 503-536.

Chiarella, C., He, X. and Hommes, C. (2006), 'A dynamic analysis of technical trading rules in financial markets', Journal of Economic Dynamics and Control 30, 1729-1753.

Chiarella, C., He, X., Huang, W. and Zheng, H. (2012), 'Estimating behavioural heterogeneity under regime switching', Journal of Economic Behavior and Organization 83, 446-460.

Chiarella, C., He, X. and Zwinkels, R. (2014), 'Heterogeneous expectations in asset pricing: empirical evidence from the S\&P 500', Journal of Economic Behavior and Organization 105, 1-16.

Chiarella, C., ter Ellen, S., He, X. and Wu, E. (2015), 'Fear or fundamentals? Heterogeneous beliefs in the European sovereign CDS market', Journal of Empirical Finance, accepted, doi:10.1016/j.jempfin.2014.11.003.

Chung, C.-F. (1999), Estimating the fractionally integrated garch model, discussion paper, National Taiwan University.

Day, R. and Huang, W. (1990), 'Bulls, bears and market sheep', Journal of Economic Behavior and Organization 14, 299-329.

De Grauwe, P. and Grimaldi, M. (2006), 'Exchange rate puzzles: A tale of switching attractors', European Economic Review 50, 1-33.

de Jong, E., Verschoor, W. and Zwinkels, R. (2010), 'Heterogeneity of agents and exchange rate dynamics: Evidence from the EMS', Journal of International Money and Finance 29(8), 1652-1669.

DeLong, J., Shleifer, A., Summers, L. and Waldmann, R. (1990), 'Noise trader risk in financial markets', Journal of Political Economy 98, 703-738.

Dieci, R., Foroni, I., Gardini, L. and He, X. (2006), 'Market mood, adaptive beliefs and asset price dynamics', Chaos, Solitons and Fractals 29, 520-534. 
Farmer, J. and Joshi, S. (2002), 'The price dynamics of common trading strategies', Journal of Economic Behavior and Organization 49, 149-171.

Franke, R. (2009), 'Applying the method of simulated moments to estimate a small agent-based asset pricing model', Journal of Empirical Finance 16, 804-815.

Franke, R. and Westerhoff, F. (2011), 'Estimation of a structural stochastic volatility model of asset pricing', Computational Economics 38, 53-83.

Franke, R. and Westerhoff, F. (2012), 'Structural stochastic volatility in asset pricing dynamics: Estimation and model contest', Journal of Economic Dynamics and Control 36, 1193-1211.

Frankel, J. and Froot, K. (1990), 'Chartists, fundamentalists and trading in the foreign exchange market', American Economic Review 80, 181-185.

Frijns, B. and T. Lehnert, R. Z. (2010), 'Behavioral heterogeneity in the option market', Journal of Economic Dynamics and Control 34, 2273-2287.

Gaunersdorfer, A., Hommes, C. and Wagener, F. (2008), 'Bifurcation routes to volatility clustering under evolutionary learning', Journal of Economic Behavior and Organization 67, 27-47.

Geweke, J. (2006), Computational experiments and reality, working paper, University of Iowa.

Gilli, M. and Winker, P. (2003), 'A global optimization heuristic for estimating agent-based model', Computational Statistics and Data Analysis 42, 299-312.

Goldbaum, D. and Mizrach, B. (2008), 'Estimating the intensity of choice in a dynamic mutual fund allocation decision', Journal of Economic Dynamics and Control 32(12), 3866-3876.

Gray, G. and Kolda, T. (2006), 'Algorithm 856: APPSPACK 4.0: Asynchronous parallel pattern search for derivative-free optimization', ACM Transactions on Mathematical Software 32(3), 485-507.

Griffin, J. and Kolda, T. (2006), Asynchronous parallel generating set search for linearly-constrained optimization, Technical report, Sandia National Laboratories, Albuquerque, NM

He, X. (2003), Asset pricing, volatility and market behaviour-a market fraction approach, Technical Report 95, Quantitative Finance Research Center, University of Techonology, Sydney.

He, X. and Li, Y. (2007), 'Power law behaviour, heterogeneity, and trend chasing', Journal of Economic Dynamics and Control 31, 3396-3426.

He, X. and Li, Y. (2008), 'Heterogeneity, convergence and autocorrelations', Quantitative Finance 8, 58-79.

He, X.-Z. and Li, Y. (2015), 'Testing of a market fraction model and power-law behaviour in the DAX 30', Journal of Empirical Finance 31, 1-17.

He, X., Li, K. and Wang, C. (2015), Volatility clustering: A nonlinear theoretical approach, Technical report, Quantitative Finance Research Centre, University of Technology, Sydney.

Heckman, J. (2001), 'Micro data, heterogeneity, and evaluation of public policy: Nobel lecture', Journal of Political Economy 109(4), 673-748.

Hnatkovska, V., Marmer, V. and Tang, Y. (2012), 'Comparison of misspecified calibrated models: The minimum distance approach', Journal of Econometrics 169(1), 131-138.

Hommes, C. (2001), 'Financial markets as nonlinear adaptive evolutionary systems', Quantitative Finance 1, 149_ 167.

Hommes, C. H. (2006), Heterogeneous agent models in economics and finance, in L. Tesfatsion and K. L. Judd, eds, 'Handbook of Computational Economics', Vol. 2 of Handbook of Computational Economics, Elsevier, chapter 23, pp. 1109-1186.

Hommes, C., Sonnemans, J., Tuinstra, J. and Velden, H. v. d. (2005), 'Coordination of expectations in asset pricing experiments', Review of Financial Studies 18, 955-980.

Kolda, T. G. (2005), 'Revisiting asynchronous parallel pattern search for nonlinear optimization', SIAM Journal on Optimization 16(2), 563-586.

LeBaron, B. (2006), Agent-based computational finance, in L. Tesfatsion and K. L. Judd, eds, 'Handbook of Computational Economics', Vol. 2 of Handbook of Computational Economics, Elsevier, chapter 24, pp. 11871233.

Li, Y., Donkers, B. and Melenberg, B. (2006), The non- and semiparametric analysis of ms models: Some applications, CentER Discussion Paper 2006-95, Tilburg University.

Li, Y., Donkers, B. and Melenberg, B. (2010), 'Econometric analysis of microscopic simulation models', Quantitative Finance 10, 1187-1201.

Lux, T. (1995), 'Herd behaviour, bubbles and crashes', Economic Journal 105, 881-896.

Lux, T. (1998), 'The socio-economic dynamics of speculative markets: Interacting agents, chaos, and the fat tails of return distributions', Journal of Economic Behavior and Organization 33, 143-165.

Lux, T. (2009a), 'Rational forecasts or social opinion dynamics? Identification of interaction effects in a business climate survey', Journal of Economic Behavior and Organization 72, 638-655.

Lux, T. (2009b), Stochastic behavioural asset pricing and stylized facts, in T. Hens and K. Schenk-Hoppe, eds, 'Handbook of Financial Markets: Dynamics and Evolution', North-Holland, Elsevier, pp. 161-215. 
Lux, T. (2012), 'Estimation of an agent-based model of investor sentiment formation in financial markets', Journal of Economic Behavior and Organization 36, 1284-1302.

Lux, T. and Marchesi, M. (1999), 'Scaling and criticality in a stochastic multi-agent model of a financial markets', Nature 397(11), 498-500.

Menkhoff, L. (1998), 'The noise trading approach — questionnaire evidence from foreign exchange', Journal of International Money and Finance 17, 547-564.

Menkhoff, L. (2010), 'The use of technical analysis by fund managers: International evidence', Journal of Banking and Finance 34, 2573-2586.

Sargent, T. (1993), Bounded Rationality in Macroeconomics, Clarendon Press, Oxford.

Shefin, H. (2005), A Behavioral Approach to Asset Pricing, Academic Press Inc., London.

Taylor, M. and Allen, H. (1992), 'The use of technical analysis in the foreign exchange market', Journal of International Money and Finance 11, 304-314.

ter Ellen, S., Verschoor, W. and Zwinkels, R. (2013), 'Dynamic expectation formation in the foreign exchange market', Journal of International Money and Finance 37, 75-97.

ter Ellen, S. and Zwinkels, R. (2010), 'Oil price dynamics: a behavioral finance approach with heterogeneous agents', Energy Economics 32, 1427-1434.

Vigfusson, R. (1997), 'Switching between chartists and fundamentals: a Markov regime-switching approach', International Journal of Finance and Economics 2, 291-305.

Westerhoff, F. and Reitz, S. (2003), 'Nonlinearities and cyclical behavior: The role of chartists and fundamentalists', Studies in Nonlinear Dynamics and Econometrics 7(4), article no. 3. 